\title{
Clear-cornea cataract surgery: pupil size and shape changes, along with anterior chamber volume and depth changes. A Scheimpflug imaging study
}

Anastasios John

Kanellopoulos ${ }^{1,2}$

George Asimellis'

'Laservision.gr Eye Institute, Athens, Greece; ${ }^{2}$ New York University School of Medicine, New York, NY, USA
Correspondence: Anastasios John Kanellopoulos

Laservision.gr Eye Institute, 17 Tsocha str, Athens II52I, Greece

Tel +302107472777

Fax +30 210 7472789

Email ajk@brilliantvision.com
This article was published in the following Dove Press journal:

Clinical Ophthalmology

24 October 2014

Number of times this article has been viewed

Purpose: To investigate, by high-precision digital analysis of data provided by Scheimpflug imaging, changes in pupil size and shape and anterior chamber (AC) parameters following cataract surgery.

Patients and methods: The study group (86 eyes, patient age $70.58 \pm 10.33$ years) was subjected to cataract removal surgery with in-the-bag intraocular lens implantation (pseudophakic). A control group of 75 healthy eyes (patient age 51.14 \pm 16.27 years) was employed for comparison. Scheimpflug imaging (preoperatively and 3 months postoperatively) was employed to investigate central corneal thickness, $\mathrm{AC}$ depth, and $\mathrm{AC}$ volume. In addition, by digitally analyzing the black-and-white dotted line pupil edge marking in the Scheimpflug "large maps," the horizontal and vertical pupil diameters were individually measured and the pupil eccentricity was calculated. The correlations between AC depth and pupil shape parameters versus patient age, as well as the postoperative AC and pupil size and shape changes, were investigated.

Results: Compared to preoperative measurements, AC depth and AC volume of the pseudophakic eyes increased by $0.99 \pm 0.46 \mathrm{~mm}(39 \% ; P<0.001)$ and $43.57 \pm 24.59 \mathrm{~mm}^{3}(36 \% ; P<0.001)$, respectively. Pupil size analysis showed that the horizontal pupil diameter was reduced by $-0.27 \pm 0.22 \mathrm{~mm}$ $(-9.7 \% ; P=0.001)$ and the vertical pupil diameter was reduced by $-0.32 \pm 0.24 \mathrm{~mm}(-11 \%$; $P<0.001)$. Pupil eccentricity was reduced by $-39.56 \% ; P<0.001$

Conclusion: Cataract extraction surgery appears to affect pupil size and shape, possibly in correlation to AC depth increase. This novel investigation based on digital analysis of Scheimpflug imaging data suggests that the cataract postoperative photopic pupil is reduced and more circular. These changes appear to be more significant with increasing patient age.

Keywords: cataract removal, anterior chamber, pupil size, pupil eccentricity, Scheimpflug imaging, pupil changes, pseudophakic eyes, postoperative myosis

\section{Introduction}

The Pentacam ${ }^{\circledR}$ (Oculus Optikgeräte $\mathrm{GmbH}$, Wetzlar, Germany) diagnostic device employs a rotating Scheimpflug camera to offer a comprehensive, three-dimensional representation of the anterior chamber (AC) from the cornea up to the crystalline lens posterior surface. Scheimpflug imaging technology offers highly repeatable and reproducible measurements of central corneal thickness (CCT), as suggested by several reports in the peer-reviewed literature. ${ }^{1-3}$ Scheimpflug imaging is employed by the authors' group in cataract patient screening and evaluation. ${ }^{4}$

In addition to multiple representations of the anterior segment, an extensive array of key anterior data is provided, ${ }^{5,6}$ as well as several parameters (eg, progression index, 
relational thickness) that aid sensitivity and specificity in screening refractive surgery patients. ${ }^{7}$ The system is widely in use, and is considered by many clinicians to be an indispensable diagnostic and surgical planning tool..$^{8-10}$

As part of the standard clinical protocol of preoperative screening and postoperative follow-up assessment of cataract surgery patients, ${ }^{4}$ the authors employ Scheimpflug imaging for a number of reasons, such as nucleus staging and the recently available densitometry measurement of the crystalline lens and cornea. ${ }^{11}$ The rising importance of such measurements may become relevant to cataract surgeons practicing in countries where third-party payers may require documentation of a need for cataract surgery independent of, or in addition to, visual acuity or contrast sensitivity clinical measurements. $^{12}$

One little-studied parameter, however, that may have clinical significance in the visual rehabilitation of the pseudophakic eye is related to the changes induced in pupil size and shape as a result of cataract surgery. Scheimpflug systems currently report, by default, an average pupil size (diameter) calculated from the three-dimensional model computed by ray tracing.

The aim of this work was to provide a novel investigation of pupil size and shape changes following cataract surgery based on a novel digital analysis procedure of "large maps" provided by the Scheimpflug system, which offers independent horizontal and vertical pupil size diameter measurement and enables precise pupil size and shape analysis.

\section{Materials and methods}

This prospective, observational, longitudinal study received approval by the Ethics Committee of Laservision.gr Eye Institute, adherent to the tenets of the Declaration of Helsinki. The study lasted 3 months during the last quarter of 2013. Informed consent was obtained from each subject at the time of the first clinical visit.

\section{Patient inclusion criteria}

Eighty-six eyes enrolled for primary cataract removal surgery constituted the study group (group A). They belonged to 54 consecutive patients presented to the authors' institution (Laservision.gr Eye Institute, Athens, Greece) for cataract surgery, with a mean \pm standard deviation age of $70.58 \pm 10.33$ years (range $42-89$ years). No cases with anisocoria, pupillary unrest, parasympathetic denervation, or other pupil defects, intraoperative complications (ie, capsular rupture), or postoperative complications were included in the study. One eye was randomly selected (employing randomization tables) from each patient if bilateral surgery was performed. A control group (group B) of 75 eyes (patient age 53.14 \pm 16.27 ) was employed for comparison. They were randomly selected during the same clinical days of the study duration from the pool of screening patients and diagnosed as non-cataract, "healthy" by a complete ophthalmological evaluation (save for refractive error) performed by the same ophthalmologist (AJK) following the same examination protocols applicable to group A. The patient demographics of both groups are shown in Table 1 .

\section{Surgical technique}

All eyes in group A underwent cataract surgery performed in the authors' institution by the same skilled surgeon (AJK). ${ }^{13}$ Employing topical anesthesia and a $2.75 \mathrm{~mm}$ clear corneal incision in the superior quadrant (between the tenth to eleventh hour), subsequent viscoelastic-divided nucleus fragment emulsification was facilitated by pulsed ultrasound offered by the Constellation ${ }^{\circledR}$ phacoemulsification system (Alcon Surgical, Fort Worth, TX, USA), lasting $43 \pm 25$ seconds on average. Following irrigation and cortex aspiration and in-the-capsularbag intraocular lens (IOL) implantation; the AcrySof ${ }^{\mathbb{B}}$ IQs (Alcon) were implanted within the intact capsular bag in all eyes. These one-piece IOLs - made up of a hydrophobic acrylic material with a refractive index (n) of 1.55 - have a biconvex aspheric design, and were used either in spherical correction or when projected postoperative astigmatism was estimated to be over $0.50 \mathrm{D}$; a toric version of the same IOL was used for astigmatism correction (toric versions T2-T7). IOL optical diameter was $6.0 \mathrm{~mm}$ in all cases. The postoperative regimen consisted of a combination of antibiotic and corticosteroid drops (dexamethasone and tobramycin) for 4 weeks.

Table I Demographics of pseudophakic patients (group A) and controls (group B)

\begin{tabular}{|c|c|c|c|c|}
\hline & \multicolumn{2}{|l|}{ Group A } & \multicolumn{2}{|l|}{ Group B } \\
\hline & Mean \pm SD & Range (min-max) & Mean \pm SD & Range (min-max) \\
\hline Age, years & $70.58 \pm 10.33$ & $42-89$ & $53.14 \pm 16.27$ & $35-64$ \\
\hline Sex, \% female & $60 \%$ & & $58 \%$ & \\
\hline Laterality, \% right eye & $53 \%$ & & $49 \%$ & \\
\hline
\end{tabular}

Abbreviations: min, minimum; max, maximum; SD, standard deviation. 


\section{Imaging, measurement, and analysis}

Scheimpflug imaging was performed with the WaveLight ${ }^{\mathbb{B}}$ Oculyzer II (Alcon), a Pentacam-based device. The Oculyzer is incorporated into the WaveLight Refractive Suite (Alcon). ${ }^{14,15}$ The device was running on software version $1.17 \mathrm{r} 47$, and the default settings of $25 \mathrm{~B}$-scans per acquisition was employed. The system employs a "cool" blue lightemitting diode with peak intensity at $475 \mathrm{~nm}$ wavelength. The source was tested with an optical laboratory-grade portable spectrograph (USB2000+; Ocean Optics, Dunedin, FL, USA). The spectral distribution had a Gaussian profile, full width at half maximum bandwidth of $28 \mathrm{~nm}$ (half intensity wavelength $458 \mathrm{~nm}$ and $487 \mathrm{~nm}$ ), and base (sound intensity level wavelength) between $438-511 \mathrm{~nm}$. At the surface of the cornea, the light intensity was measured as $4.79 \times 10^{-2} \mathrm{~mW} / \mathrm{cm}^{2}$ at the maximum intensity of $475 \mathrm{~nm}$ (Pentacam Oculus data).

Exact lighting conditions (dim ambient lighting being the standard in the examination room) as well as measurement duration were maintained for all acquisitions. The blue light was "on" for 10 seconds before each capture to ensure that the pupil had time to adjust to the specific lighting conditions.

For group A, measurements from the preoperative and 3-month postoperative clinical visit were used. For group B, measurements from the most recent clinical visit were included in the study.

All measurements included in the study had $9.0 \mathrm{~mm}$ of cornea diameter coverage, and a minimum of $8.0 \mathrm{~mm}$ diameter

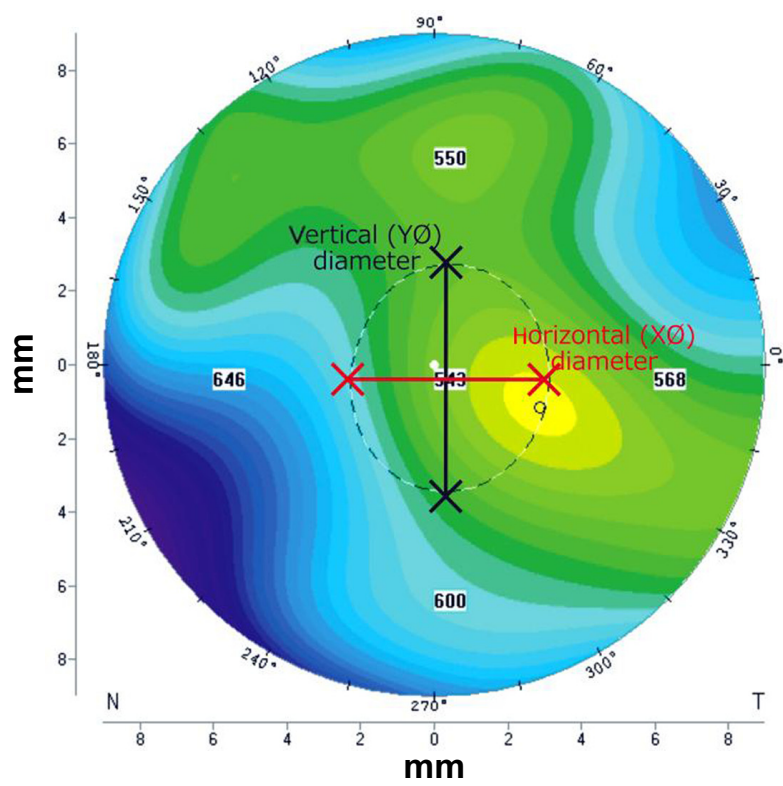

nonextrapolated data. The internal quality analysis had to indicate no issues (only "OK" and no yellow and red color in the "examination quality specification" boxes, likely due to blinking or eye movement). Measurements were performed without pupil dilation, and no myotics were employed. Examinees were asked to blink completely and briefly just before each acquisition to spread a uniform and optically smooth tear film over the cornea. To reduce operator-dependent variables, the automatic release mode was engaged.

Standard Scheimpflug reporting produced values for CCT, AC depth, and AC volume. AC depth (external) corresponds to the distance from the corneal epithelium (anterior cornea) to the lens capsule anterior surface. Because the system failed to automatically report AC depth value in the majority of postoperative cases $(87 \%)$ - probably due to lack of anterior "lens" surface identification, AC depth was measured onscreen by the available caliper tool in all postoperative cases of group A.

In each case, the corresponding corneal thickness "large map" was processed by a proprietary software developed in-house, initially designed to digitally measure femtosecond laser-assisted in situ keratomileusis (LASIK) flap diameter from intraoperative imagery by identification of the side-cut flap boundary. ${ }^{16-18}$ In the present work, the black-and-white dotted line marking the pupil edge imaged on the Scheimpflug "large maps" (Figure 1) was employed to measure both the horizontal (XØ) and vertical (YØ) pupil diameter.

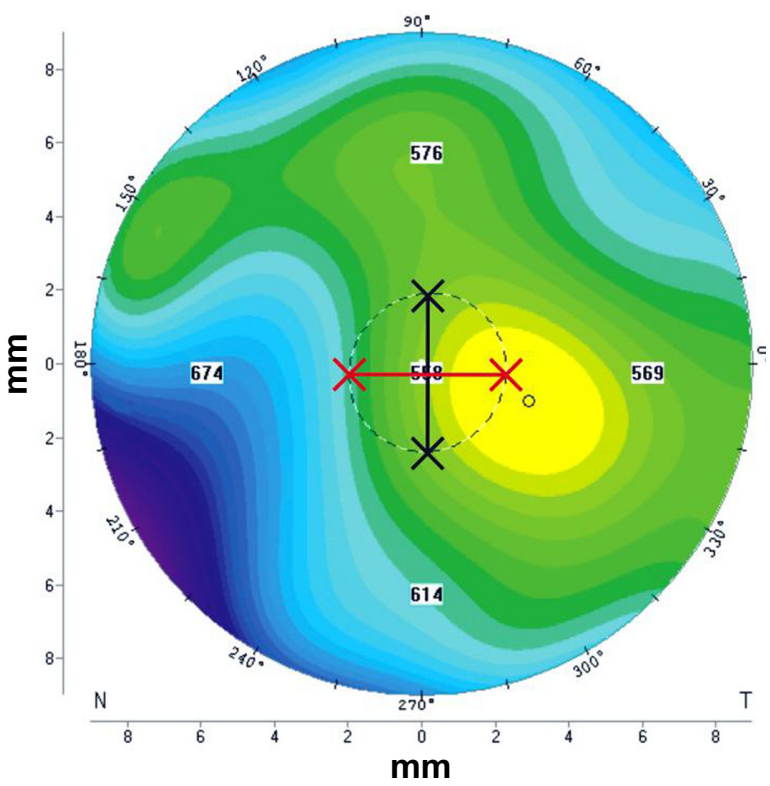

Figure I Preoperative (left) and postoperative (right) "large map" images showing corneal thickness of the same eye.

Notes: The black-and-white dotted line marking the pupil edge was digitally analyzed to produce the horizontal and vertical pupil diameter, as well as eccentricity. Preoperatively, the horizontal diameter was $2.66 \mathrm{~mm}$, the vertical diameter was $3.06 \mathrm{~mm}$, and eccentricity was 0.50 . Postoperatively, the horizontal diameter was $2.14 \mathrm{~mm}$, the vertical diameter was $2.14 \mathrm{~mm}$, and eccentricity was 0.00 .

Abbreviations: $\mathrm{X} \varnothing$, horizontal pupil diameter; $Y \varnothing$, vertical pupil diameter. 
Subsequently, the pupil eccentricity $(E E)$ was calculated using the formula:

$$
E E=\frac{\sqrt{a^{2}-b^{2}}}{a},
$$

where $a$ was the largest of the horizontal (XØ) or the vertical (YØ) pupil semi-diameter and $b$ was the smallest, respectively.

Ocular axial length was measured preoperatively in all cases by the WaveLight OB820 biometer (Alcon). ${ }^{4}$ The OB820 is based on the Lenstar LS900 ${ }^{\circledR}$ (Haag-Streit AG, Koeniz, Switzerland), a multifunctional, noncontact optical biometer employing a superluminescent diode laser centered at a wavelength of $820 \mathrm{~nm}$. Operating on the optical low-coherence reflectometry principle, the system provides keratometry and axial eye dimensions and suggests a selection of IOL strengths based on established calculation formulas. ${ }^{19-21}$ The OB820 was also used in this study to provide AC depth and central crystalline lens thickness measurements in both groups.

Linear regression analysis was performed to seek possible correlations. Descriptive and comparative statistics and analysis of variance between various parameters were performed with statistics tools provided by Minitab ${ }^{\circledR}$ version 16.2.3 (Minitab Ltd., Coventry, UK) and IBM SPSS ${ }^{\circledR}$ version 21.0 (IBM Corporation, New York, NY, USA). A $P$-value less than 0.05 was considered an indication of statistical significance.

\section{Results}

Up to the 3-month postoperative interval, the clinical condition was assessed as normal in all eyes, as evaluated by a complete ophthalmological examination. The postoperative mean spherical equivalent refraction was $0.25 \pm 0.37 \mathrm{D}$ (target was emmetropia in all cases) in the study group, and mean corrected distance visual acuity was $0.022 \pm 0.005 \log$ MAR.
Slit-lamp examination confirmed that all eyes in the study group had good IOL centration, no tilt, and no postoperative complications (eg, posterior capsule opacification). No eye had a window defect or other detectable alterations/trauma of the iris, and proper pupil light responsiveness was validated.

\section{Anterior segment parameters: preoperative and control group comparison}

The axial length, as measured by the OB820 device, was $24.76 \pm 2.3(19.73-34.15) \mathrm{mm}$ in the study group and $23.69 \pm 1.17(19.70-33.05) \mathrm{mm}$ in the control group. No statistically significant difference was identified between the two groups $(P=0.183)$ (Table 2). AC depth was measured by both the Scheimpflug imaging device (Oculyzer) and the interferometric biometry device (OB820). The AC depth values were significantly different between the preoperative cataract group and the control group for both modalities employed $(P=0.024$ and $P=0.019$, respectively) (Table 2 ). The central crystalline lens thickness was measured in both groups by the OB820 device. It was $4.44 \pm 0.91(3.21-4.78) \mathrm{mm}$ in group A and $3.35 \pm 0.78(2.82-4.35) \mathrm{mm}$ in group $\mathrm{B}(P<0.05)$.

The subsequent IOL power implanted in the group A eyes was $19.2 \pm 3.9(6.0-28.0) \mathrm{D}$.

The values for pupil diameter, as reported by the Scheimpflug device and as measured separately for the horizontal and vertical diameter (XØ and $\mathrm{Y} \varnothing)$ by the proprietary digital analysis software, are reported in Table 2 . The pupil diameter was $2.83 \pm 0.53(1.83-4.13) \mathrm{mm}$ for preoperative group A and 3.03 $\pm 0.31(2.43-3.93) \mathrm{mm}$ for group B. The horizontal diameter was $2.77 \pm 0.47(1.92-4.09) \mathrm{mm}$ and $3.02 \pm 0.19(2.42-3.91) \mathrm{mm}$ for preoperative group A and group B, respectively. The vertical diameter was $2.86 \pm 0.49$ (1.95-4.20) $\mathrm{mm}$ and 3.04 $\pm 0.14(2.43-3.93) \mathrm{mm}$ for preoperative group A and group B, respectively. The pupil size

Table 2 Anterior chamber depth and axial length of pseudophakic patients (group A) and controls (group B)

\begin{tabular}{|c|c|c|c|c|c|}
\hline \multirow[t]{2}{*}{ Parameter } & \multicolumn{2}{|c|}{ Group A (preoperative) } & \multicolumn{2}{|l|}{ Group B } & \multirow[t]{2}{*}{$P$-value } \\
\hline & Mean \pm SD & Range (min-max) & Mean \pm SD & Range (min-max) & \\
\hline $\mathrm{AC}$ depth, ${ }^{+} \mathrm{mm}$ & $3.26 \pm 0.43$ & $2.34-4.15$ & $3.50 \pm 0.24$ & $2.43-4.26$ & 0.024 \\
\hline AC depth,* mm & $3.28 \pm 0.45$ & $2.35-4.15$ & $3.52 \pm 0.23$ & $2.44-4.27$ & 0.019 \\
\hline Axial length, ${ }^{+} \mathrm{mm}$ & $24.76 \pm 2.3$ & $19.73-34.15$ & $23.69 \pm 1.17$ & $19.70-33.05$ & 0.183 \\
\hline Pupil diameter,* mm & $2.83 \pm 0.53$ & $1.83-4.13$ & $3.03 \pm 0.31$ & $2.43-3.93$ & 0.039 \\
\hline Horizontal pupil diameter $(X \varnothing), \mathrm{mm}$ & $2.77 \pm 0.47$ & $1.92-4.09$ & $3.02 \pm 0.19$ & $2.42-3.91$ & 0.032 \\
\hline Vertical pupil diameter (YØ), mm & $2.86 \pm 0.49$ & $1.95-4.20$ & $3.04 \pm 0.14$ & $2.43-3.93$ & 0.029 \\
\hline
\end{tabular}

Notes: ${ }^{+}$As reported by the WaveLight ${ }^{\oplus}$ OB820 biometry system (Alcon Laboratories, Fort Worth, TX, USA). *As reported by the WaveLight ${ }^{\oplus}$ Oculyzer II (Alcon) Scheimpflug imaging system. Study group A values are preoperative. Horizontal and vertical pupil diameters $(X \varnothing$ and $Y \varnothing)$ were measured by the proprietary digital analysis software.

Abbreviations: AC, anterior chamber; min, minimum; max, maximum; SD, standard deviation. 
Table 3 Preoperative and 3-month postoperative pupil measurements and difference between preoperative and postoperative measurements of anterior chamber depth, anterior chamber volume, central corneal thickness, pupil diameter, horizontal pupil diameter, and vertical pupil diameter

\begin{tabular}{|c|c|c|c|c|c|}
\hline \multirow[t]{2}{*}{ Parameter } & \multicolumn{2}{|l|}{ Preoperative } & \multicolumn{2}{|c|}{ Postoperative } & \multirow[t]{2}{*}{$P$-value } \\
\hline & Mean \pm SD & Range (min-max) & Mean \pm SD & Range (min-max) & \\
\hline AC depth (external), mm & $3.26 \pm 0.43$ & $2.34-4.15$ & $4.25 \pm 0.42$ & $3.20-5.25$ & $<0.001$ \\
\hline AC volume, $\mathrm{mm}^{3}$ & $149.79 \pm 43.00$ & $62-240$ & $193.70 \pm 30.29$ & $127-269$ & $<0.001$ \\
\hline $\mathrm{CCT}, \mu \mathrm{m}$ & $538.70 \pm 41.49$ & $439-616$ & $544.57 \pm 44.39$ & $432-634$ & 0.3724 \\
\hline Pupil diameter,* mm & $2.83 \pm 0.53$ & $1.83-4.13$ & $2.56 \pm 0.50$ & $1.7 \mid-4.04$ & 0.0368 \\
\hline Horizontal pupil diameter $(X \varnothing), \mathrm{mm}$ & $2.77 \pm 0.47$ & $1.92-4.09$ & $2.50 \pm 0.4 \mathrm{I}$ & $1.73-3.76$ & 0.0001 \\
\hline Vertical pupil diameter (YØ), mm & $2.86 \pm 0.49$ & $1.95-4.20$ & $2.54 \pm 0.42$ & $1.73-3.90$ & $<0.001$ \\
\hline
\end{tabular}

Notes: *As reported by the WaveLight ${ }^{\circledR}$ Oculyzer II (Alcon Laboratories, Fort Worth, TX, USA) Scheimpflug imaging system.

Abbreviations: AC, anterior chamber; CCT, central corneal thickness; min, minimum; max, maximum; SD, standard deviation.

dimensions were significantly different $(P=0.039, P=0.032$, and $P=0.029$, respectively).

\section{Anterior segment and pupil size: preoperative versus postoperative comparison}

Table 3 summarizes the preoperative versus postoperative values for specific anterior segment parameters (AC depth, AC volume, and CCT) measured in group A by the Scheimpflug device. CCT was 538.70 \pm 41.49 (439-616) $\mu \mathrm{m}$ preoperatively and $544.57 \pm 44.39$ (432-634) $\mu \mathrm{m}$ postoperatively $(P=0.3724)$. AC depth and volume significantly increased. AC depth was $3.26 \pm 0.43(2.34-4.15) \mathrm{mm}$ preoperatively and $4.25 \pm 0.42(3.20-5.25) \mathrm{mm}$ postoperatively $(P<0.001)$. AC volume was $149.79 \pm 43.00(62-240) \mathrm{mm}^{3}$ preoperatively and $193.70 \pm 30.29(127-269) \mathrm{mm}^{3}$ postoperatively $(P<0.001)$. Figure 2 illustrates $\mathrm{AC}$ volume change, expressed as a percentage of the preoperative value, as a result of cataract surgery in the form of a fitted line plot versus patient age.

Pupil diameter also showed a statistically significant change towards a smaller postoperative average diameter. Specifically, pupil diameter, as reported by the Scheimpflug system, was $2.83 \pm 0.53(1.83-4.13) \mathrm{mm}$ preoperatively and $2.66 \pm 0.50$ (1.71-4.04) mm postoperatively $(P=0.0368)$. The horizontal pupil diameter (XØ) was $2.77 \pm 0.47(1.92-4.09) \mathrm{mm}$ preoperatively and $2.50 \pm 0.41(1.73-3.76) \mathrm{mm}$ postoperatively $(P=0.0001)$, and the vertical pupil diameter (YØ) was $2.86 \pm 0.49(1.95-4.20) \mathrm{mm}$ preoperatively and $2.54 \pm 0.42$ $(1.73-3.90)$ mm postoperatively $(P<0.001)$. Figure 3 illustrates

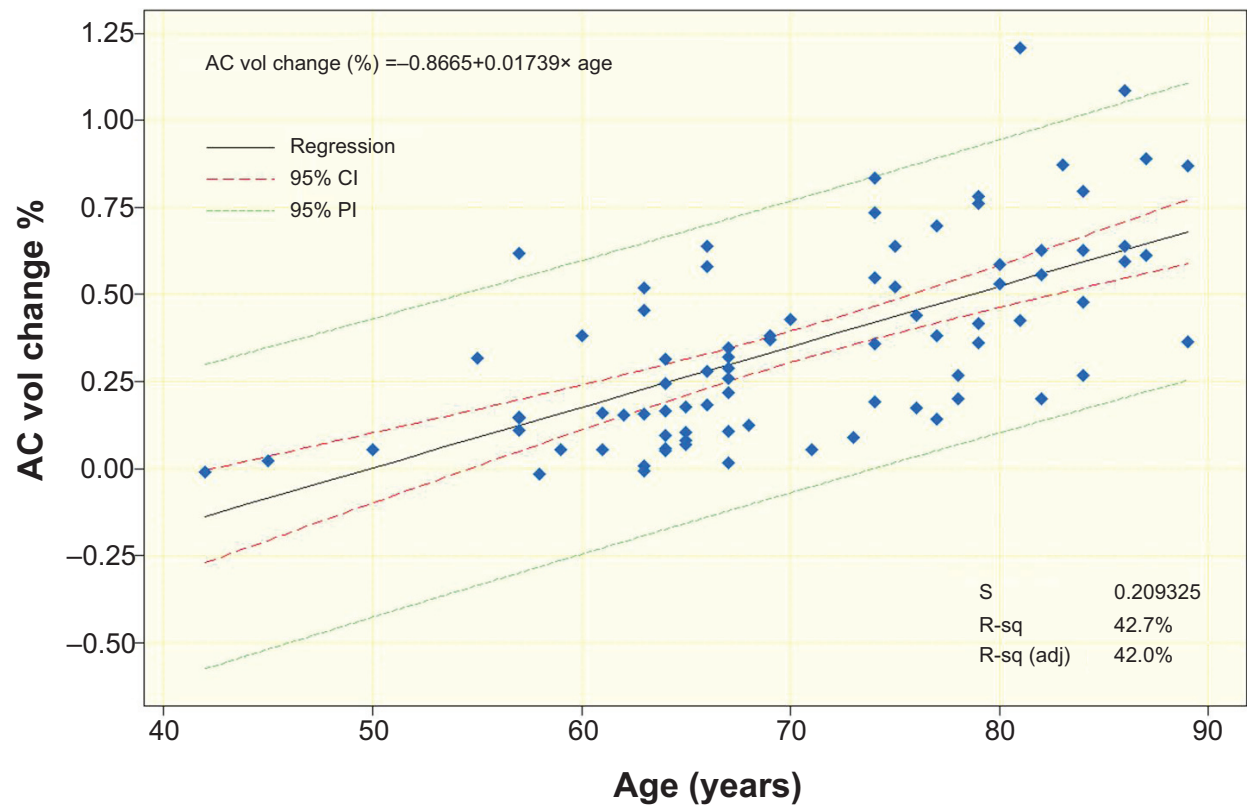

Figure 2 A fitted line plot of anterior chamber volume change, expressed as a percentage of the preoperative value, as a result of cataract surgery ( $\mathrm{n}=86$ eyes) versus patient age. Abbreviations: AC, anterior chamber; Cl, confidence interval; Pl, prediction interval; R-sq, coefficient of determination; R-sq (adj), adjusted coefficient of determination; S, sum of residuals; vol, volume. 
the pupil diameter change (horizontal in Figure $3 \mathrm{~A}$ and vertical in Figure 3B), expressed as a percentage of the preoperative value, as a result of cataract surgery in the form of a fitted line plot versus patient age.

\section{Pupil eccentricity: preoperative versus postoperative comparison}

Pupil eccentricity was computed on the basis of the formula introduced in the Material and methods section. As shown in Table 4, pupil eccentricity was $0.183 \pm 0.208(-0.43-0.566)$ preoperatively and $0.130 \pm 0.134(0.26-0.308)$ postoperatively $(P=0.049)$. Even more interesting was the distribution of the eccentricity values.
By definition, eccentricity is positive, ranging from zero for a perfect circular shape (eg, $\mathrm{X} \varnothing=\mathrm{Y} \varnothing)$, to between zero and one for an elliptical shape. For example, if $Y \varnothing>\mathrm{X} \varnothing$, the pupil shape is elliptical, with the "major" axis oriented vertically. Thus, a positive eccentricity value (but less than one) corresponds to an elliptical pupil whose largest diameter lies vertically. This was the case in 64/86 (74\%) of the pupils measured. Another eleven pupils (13\%) were completely circular $(E E=0)$. However, there were eleven pupils $(13 \%)$ whose "major" axis was oriented horizontally, ie, the pupil had a larger horizontal diameter (XØ> YØ).

Thus, in similarity to the established nomenclature for astigmatism, the term "with-the-rule" was introduced to

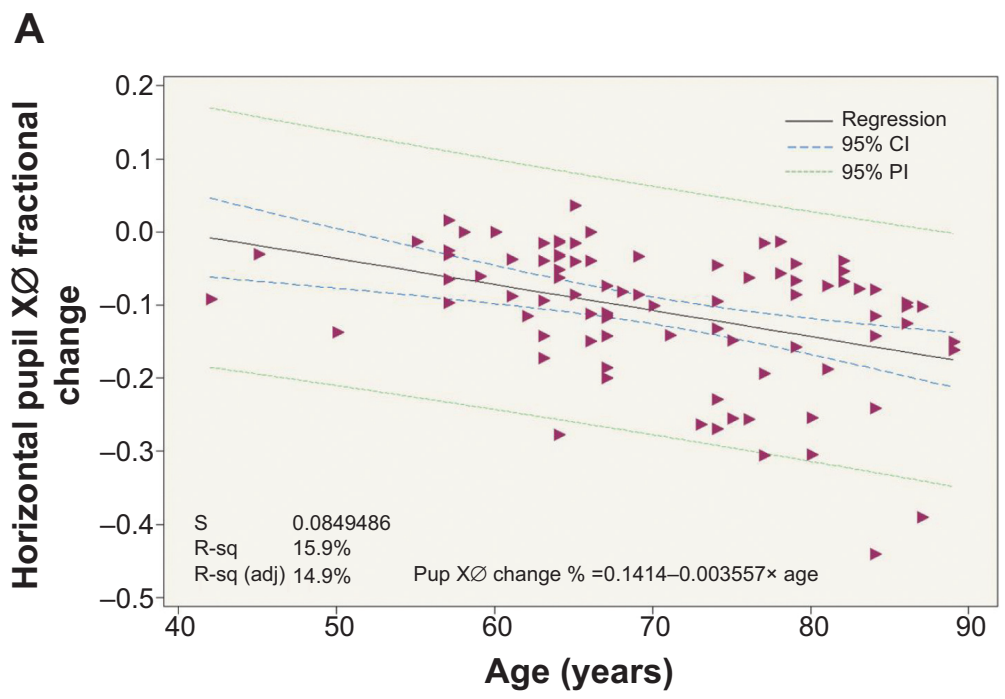

B

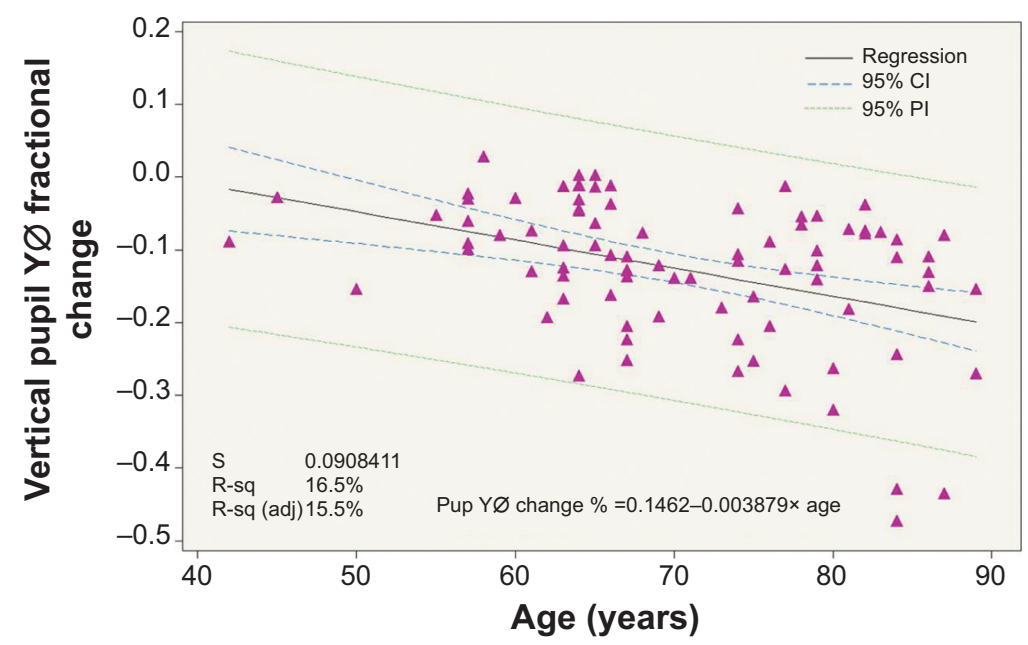

Figure 3 Fitted line plots of pupil diameter change with cataract surgery, as a function of age.

Notes: (A) A fitted line plot of horizontal pupil diameter relative change, expressed as a fraction of the preoperative value, as a result of cataract surgery ( $\mathrm{n}=86$ eyes) versus patient age. (B) A fitted line plot of vertical pupil diameter relative change, expressed as a fraction of the preoperative value, as a result of cataract surgery ( $\mathrm{n}=86$ eyes) versus patient age.

Abbreviations: $\mathrm{Cl}$, confidence interval; PI, prediction interval; Pup, pupil; R-sq, coefficient of determination; R-sq (adj), adjusted coefficient of determination; S, sum of residuals; $X \varnothing$, horizontal pupil diameter; $Y \varnothing$, vertical pupil diameter. 
Table 4 Preoperative and 3-month postoperative pupil measurements and difference between pupil eccentricity

\begin{tabular}{llllll}
\hline Parameter & Preoperative & & & Postoperative & \multicolumn{1}{c}{ P-value } \\
\cline { 2 - 3 } \cline { 5 - 6 } & Mean \pm SD & Range (min-max) & & Mean \pm SD & Range (min-max) \\
\hline Pupil eccentricity & $0.183 \pm 0.208$ & $-0.43-0.566$ & & $0.130 \pm 0.134$ & $-0.26-0.308$ \\
With-the-rule, \% & $74 \%$ & & $62 \%$ & \\
No eccentricity, \% & $13 \%$ & & $34 \%$ & \\
Against-the-rule, \% & $13 \%$ & & $5 \%$ & \\
With-the-rule & $0.288 \pm 0.091$ & $0.160-0.566$ & $0.226 \pm 0.050$ & $0.151-0.308$ \\
Against-the-rule & $-0.245 \pm 0.090$ & -0.43 to -0.157 & $-0.195 \pm 0.045$ & -0.26 to -0.166 \\
\hline
\end{tabular}

Notes: "With-the-rule" indicates pupils elongated vertically (ie, positive values). "Against-the-rule" pupils elongated horizontally (ie, negative values).

Abbreviations: SD, standard deviation; min, minimum; max, maximum.

indicate the majority of the cases, ie pupils vertically elongated, and "against-the-rule" to indicate the minority, ie, pupils horizontally elongated. To further distinguish the two cases, the eccentricity values in the "against-the-rule" cases were denoted as negative.

Postoperatively, however, pupil eccentricity distribution (Figure 4) was more circular, as indicated by $53(62 \%)$ "with-the-rule," 29 (34\%) complete circular, and only four (5\%) "against-the-rule" pupils. In addition, the "with-therule" group with vertical orientation had eccentricity reduced by a statistically significant margin, from $0.288 \pm 0.091$ to $0.226 \pm 0.050(P<0.001)$.

\section{Discussion}

Knowledge of pupil size is desirable due to the known significant effect on visual function, depending mainly on the adapting luminance, as well as a variety of other factors. ${ }^{22}$ Pupil size and shape also have a direct effect on depth of field, as well as on retinal illuminance, which in turn influence visual performance. The majority of pupillometry systems in clinical practice employ near infrared illumination to capture the image of the pupil. ${ }^{23} \mathrm{~A}$ common feature in most systems is direct eye illumination with a light source, followed by pupil image capture with a near infrared-sensitive camera. ${ }^{24}$

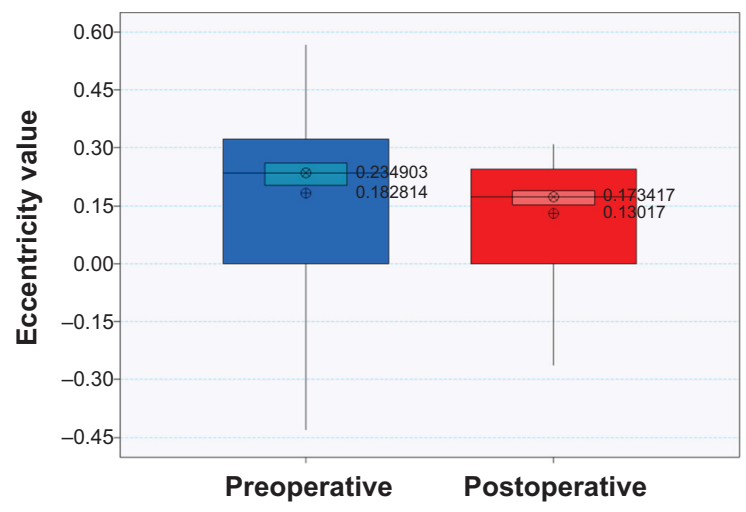

The present study evaluated the outcomes of cataract removal surgery in regard to $\mathrm{AC}$ parameters and patient age, focusing on the little-studied parameters of induced pupil size and shape as a result of cataract extraction surgery. Only a few publications in the peer-reviewed literature could be found on pupil size and shape changes following cataract surgery, which, however, either did not identify influence on pupil size and shift ${ }^{25}$ or dealt with different clinical conditions such as multifocal IOLs, ${ }^{26}$ posterior chamber phakic IOLs, ${ }^{27}$ iris-fixated IOLs ${ }^{28}$ or patients with diabetes mellitus. ${ }^{29}$

The present study suggests a statistically significant alteration in pupil size and shape following cataract surgery: the postoperative pupil size reduction averaged between $-11 \%$ and $-13 \%$. In addition, pupil eccentricity was substantially reduced $(-39 \%)$. These pupil size changes may be related to the increased $\mathrm{AC}$ depth and volume following the extraction of the bulky crystalline lens (Figure 5) - average thickness of $4.4 \mathrm{~mm}$ - and replacement with a thin IOL - thickness often $<1 \mathrm{~mm} .{ }^{30}$ The reduced IOL volume may allow for more freedom of movement of the constrictor iris muscles, thus possibly enabling their full extent. It is also likely that a preoperative reduction of iris movement constraints, possibly induced by the narrow spatial allowance due to the crystalline lens intumescence as it develops into a cataract,

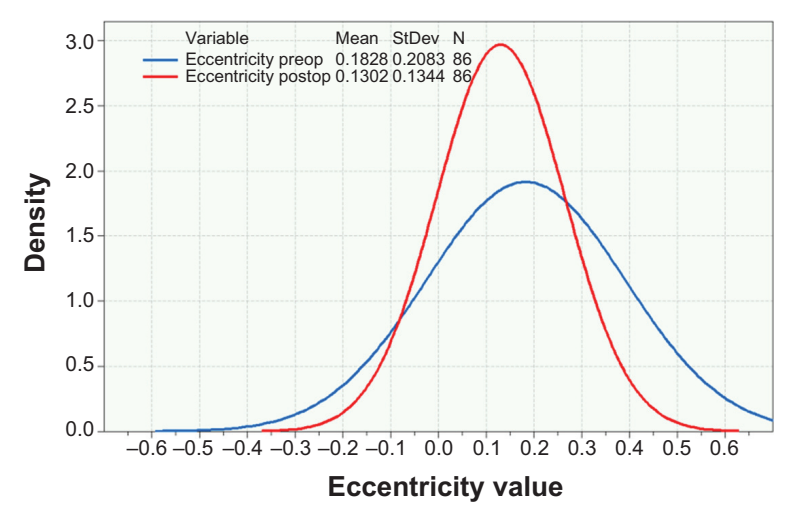

Figure 4 Preoperative (blue) and postoperative (red) pupil eccentricity in the form of box plots (left) and histogram distributions (right). Abbreviations: postop, postoperative; preop, preoperative; StDev, standard deviation. 

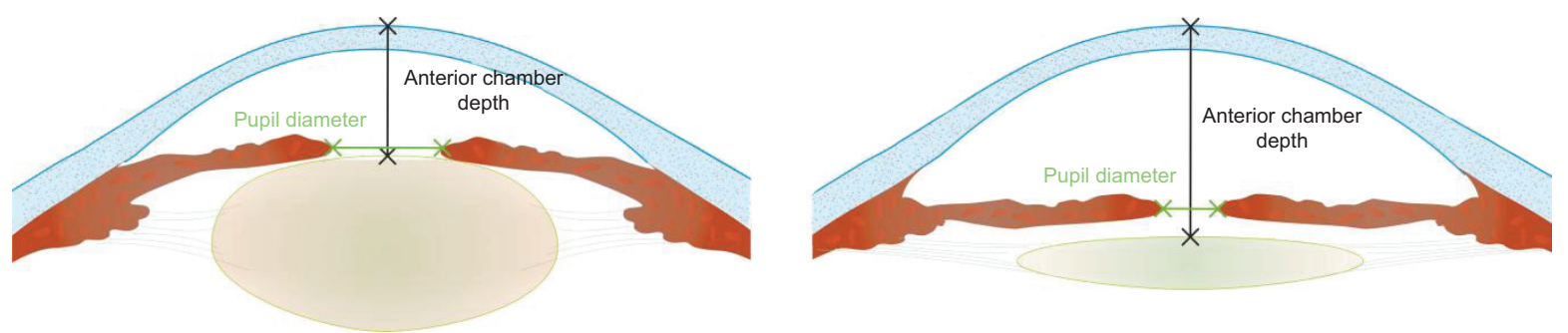

Figure 5 Graphical illustration of preoperative (left) and postoperative (right) anterior segment indicating the increase in anterior chamber volume and depth. Note: The increased freedom of movement allowing for a smaller pupil diameter is a possible contributing factor to the findings in this work of a reduced pupil diameter and more circular shape.

may be related to the asymmetries in pupil shape relating to the measured preoperative eccentricity. The radical reduction (or even elimination) of such constrains may also be a contributing factor to the more circular (less eccentric) pupil size following cataract removal surgery.

Such "myosis" may prove beneficial since halos produced by a scotopic pupil diameter exceeding the boundaries of the IOL optical zone will be less, rather than more, frequent. A smaller pupil size may also cause a "pinhole effect," leading to reduced possible effects of refractive undercorrection or overcorrection and/or residual astigmatism.

In addition, the aqueous flow through the pupillary margin may be influenced by a narrower pupil, in a manner similar to topical myotics, but deepening of the AC apparently facilitates aqueous flow through the pupillary margin.

\section{Optical considerations}

The pupil size depicted by the Scheimpflug system and measured in this study corresponds to the "true" anatomical pupil size calculated from the three-dimensional model, derived by ray tracing. As stated above, pupillometry systems report the size of the entrance pupil, ie, the virtual image of the physical pupil as imaged through the cornea. In other words, traditional pupillometry employs a simple "image capture" of the pupil, which, however, corresponds to the "entrance" pupil. As in any optical system, the entrance pupil is the magnified, virtual image of the aperture stop, ie, the anatomical pupil ${ }^{31}$ this is what any observer "sees" as a pupil, as illustrated in Figure 6. The magnification depends on the actual distance of the anatomical pupil from the cornea (approximated by the AC depth), the refractive indices (n) of the media beside the cornea, as well as the corneal refractive power. In an emmetropic eye with average total corneal power $+43 \mathrm{D}$, $\mathrm{AC}$ depth $3.6 \mathrm{~mm}$, and $\mathrm{n}_{\text {aqueous }} 1.336$, the apparent pupil is about $13.1 \%$ larger and $0.55 \mathrm{~mm}$ closer to the cornea than the anatomical pupil.

According to the visual optics calculations ${ }^{32}$ that were applied, assuming that the cornea was not subjected to refractive change in the cataract surgery cases examined herein, the pupil magnification factor of the apparent pupil was approximately $11.7 \%$ for the preoperative eyes (average AC depth $3.26 \mathrm{~mm}$ ) and $15.9 \%$ for the postoperative eyes (average AC depth $4.25 \mathrm{~mm}$ ). These results contrast, for example, to a refractive intervention by alteration of the corneal anterior curvature (eg, photo refractive keratectomy, LASIK), in which

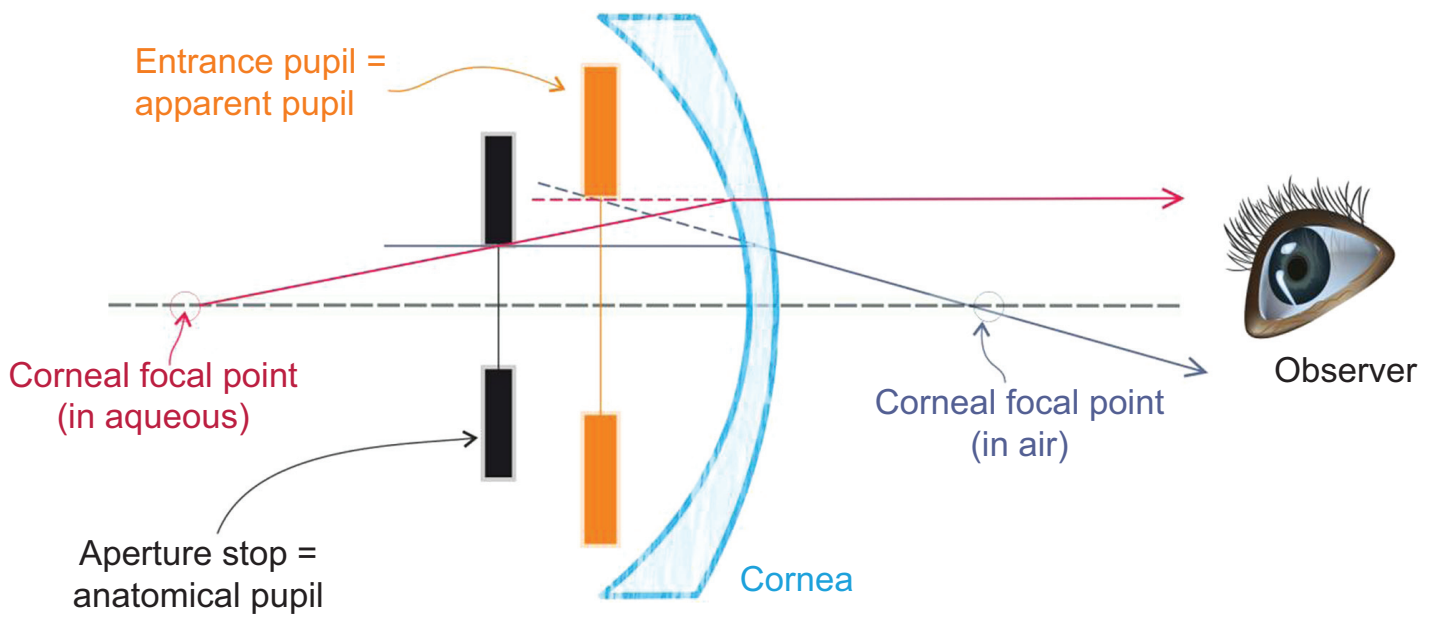

Figure 6 Graphical illustration of the anatomical pupil, as imaged through the optical system of the cornea (not to scale).

Note: The anatomical pupil is the "aperture stop," and the magnified "apparent pupil" is the entrance pupil of the optical system. 
the pupil magnification changes ${ }^{33}$ can be attributed to changes in the corneal refractive power and not the AC depth.

\section{Pupil changes and patient age}

The pupil diameter has been reported to retreat with age, ${ }^{34}$ along with accommodative and pupillary responses, possibly due to degraded iris elasticity (pupil constriction) and cornea transparency. ${ }^{35,36}$ In the present study, a near-photopic pupil diameter was measured, which appears to be restricted in reaching maximum strength (ie, minimum photopic diameter), possibly by physical inhibition with increased slope and reduced spatial movement due to the volume occupied by the bulky crystalline lens. The data suggest that there appears to be an age-related factor: the achieved AC volume change (Figure 2) as well as the AC depth change appear to be correlated with patient age. This finding is in agreement with the pupil diameter reduction (Figure $3 \mathrm{~A}$ and $\mathrm{B}$ ), which is also correlated with patient age. In other words, the findings suggest that with increasing patient age, there is more AC depth and volume increase - probably expected, as studies have indicated increased preoperative crystalline lens thickness, ${ }^{4}$ and thus the creation of more anterior segment "space." The new finding herein is the associated pupil size reduction and shape improvement with age, as the pupil appears to reach a smaller diameter and more circular shape.

The majority of pupillometry systems employ near infrared illumination to capture the pupil image. ${ }^{24,37} \mathrm{~A}$ common feature in these modalities is the direct illumination of the front of the eye with a light source along with the capture of reflected light with a near infrared-sensitive camera. ${ }^{38}$ Although these techniques are useful and have their roles, they do not provide simultaneous information about iris shape and structural detail, which could be useful in providing etiologic information about tissue factors directly affecting pupil shape, position, and function.

\section{Other considerations - limitations}

A limitation to this study is related to the fact that the pupil size measurements correspond to blue light-emitting diode light employed by the Pentacam system and not to a full range of natural light ranging from low to high intensities. The blue light stimulation may cause myosis: blue light suppresses melatonin in humans, with the strongest response occurring in the short-wavelength portion of the spectrum between $446-477 \mathrm{~nm} .{ }^{39}$ Another limitation to the study is that the Pentacam cannot analyze an accurate scotopic pupil. The study remains useful, however, since a within-cases study design was identical for all eyes examined, and thus the changes found correspond to identical lighting and stimuli conditions.
While this work investigated the influence of cataract removal surgery and IOL implantation in AC depth and pupil size and shape, it is important to acknowledge that there are many factors also influencing pupil size, such as adapting luminance, ${ }^{40}$ accommodation, ${ }^{41}$ mental activity, ${ }^{42}$ emotional state, ${ }^{43}$ and attention. ${ }^{44}$ However, the cognitive effects are quite small, and all of these factors are largely transient: the pupil returns near to its prevailing size after a short period of time. ${ }^{22}$ In addition, while a reduction in pupil diameter may be caused by pharmacological effects, ${ }^{45}$ such as acetylcholine, it has been shown that such effects are only temporary. ${ }^{46}$

\section{Conclusion}

This novel investigation of digital analysis in standard Scheimpflug imaging suggests that cataract surgery results in reduced photopic pupil size and resulted in a more circular shaped pupil. These changes appear to be more significant with advancing patient age. These findings may be useful in clinical practice when assessing post-surgery data and potentially in IOL selection and future IOL design.

\section{Disclosure}

AJK is a consultant/has an advisory position at Alcon/ WaveLight, Fort Worth, TX, USA; Allegran, Irvine, CA, USA; Avedro, Waltham, MA, USA; and i-Optics, Amsterdam, the Netherlands. GA reports no conflicts of interest in this work.

\section{References}

1. Huang J, Ding X, Savini G, et al. A comparison between Scheimpflug imaging and optical coherence tomography in measuring corneal thickness. Ophthalmology. 2013;120(10):1951-1958.

2. Huang J, Savini G, Hu L, et al. Precision of a new Scheimpflug and Placidodisk analyzer in measuring corneal thickness and agreement with ultrasound pachymetry. J Cataract Refract Surg. 2013;39(2):219-224.

3. McAlinden C, Khadka J, Pesudovs K. A comprehensive evaluation of the precision (repeatability and reproducibility) of the Oculus Pentacam HR. Invest Ophthalmol Vis Sci. 2011;52(1):7731-7737.

4. Kanellopoulos AJ, Asimellis G. Correlation between central corneal thickness, anterior chamber depth, and corneal keratometry as measured by Oculyzer II and WaveLight OB820 in preoperative cataract surgery patients. J Refract Surg. 2012;28(12):895-900.

5. Gilani F, Cortese M, Ambrosio R Jr, et al. Comprehensive anterior segment normal values generated by rotating Scheimpflug tomography. $J$ Cataract Refract Surg. 2013;39(11):1707-1712.

6. Feng MT, Belin MW, Ambrosio R Jr, et al. International values of corneal elevation in normal subjects by rotating Scheimpflug camera. J Cataract Refract Surg. 2011;37(10):1817-1821.

7. Ambrosio R Jr, Caiado AL, Guerra FP, et al. Novel pachymetric parameters based on corneal tomography for diagnosing keratoconus. J Refract Surg. 2011;27(10):753-758.

8. Kanellopoulos AJ, Asimellis G. Revisiting keratoconus diagnosis and progression classification based on evaluation of corneal asymmetry indices, derived from Scheimpflug imaging in keratoconic and suspect cases. Clin Ophthalmol. 2013;7:1539-1548. 
9. de Jong T, Sheehan MT, Dubbelman M, Koopmans SA, Jansonius NM. Shape of the anterior cornea: comparison of height data from four corneal topographers. J Cataract Refract Surg. 2013;39(10):1570-1580.

10. Khairat YM, Mohamed YH, Moftah IA, Fouad NN. Evaluation of corneal changes after myopic LASIK using the Pentacam ${ }^{\circledR}$. Clin Ophthalmol. 2013;7:1771-1776.

11. Elflein HM, Hofherr T, Berisha-Ramadani F, et al. Measuring corneal clouding in patients suffering from mucopolysaccharidosis with the Pentacam densitometry programme. Br J Ophthalmol. 2013;97(7): 829-833.

12. Ginsburg AP. Contrast sensitivity: determining the visual quality and function of cataract, intraocular lenses, and refractive surgery. Curr Opin Ophthalmol. 2006;17(1):19-26.

13. Kanellopoulos AJ. All-laser bladeless cataract surgery, combining femtosecond and nanosecond lasers: a novel surgical technique. Clin Ophthalmol. 2013;7:1791-1795.

14. Kanellopoulos AJ, Asimellis G. Long-term bladeless LASIK outcomes with the FS200 femtosecond and EX500 excimer laser workstation: the refractive suite. Clin Ophthalmol. 2013;7:261-269.

15. Kanellopoulos AJ, Asimellis G. Refractive and keratometric stability in high myopic LASIK with high-frequency femtosecond and excimer lasers. J Refract Surg. 2013;29(12):832-837.

16. Kanellopoulos AJ, Asimellis G. Digital analysis of flap parameter accuracy and objective assessment of opaque bubble layer in femtosecond laser-assisted LASIK: a novel technique. Clin Ophthalmol. 2013; $7: 343-351$.

17. Kanellopoulos AJ, Asimellis G. Essential opaque bubble layer elimination with novel LASIK flap settings in the FS200 femtosecond laser. Clin Ophthalmol. 2013;7:765-770.

18. Kanellopoulos AJ, Asimellis G. FS200 femtosecond laser LASIK flap digital analysis parameter evaluation: comparing two different types of patient interface applanation cones. Clin Ophthalmol. 2013;7:1103-1108

19. Faramarzi A, Yazdani S, Pakravan M. Central anterior chamber depth changes after prophylactic laser iridotomy. Optom Vis Sci. 2013;90(7): 707-710.

20. Huang J, Pesudovs K, Wen D, et al. Comparison of anterior segment measurements with rotating Scheimpflug photography and partial coherence reflectometry. J Cataract Refract Surg. 2011;37(2):341-348.

21. Lee AC, Qazi MA, Pepose JS. Biometry and intraocular lens power calculation. Curr Opin Ophthalmol. 2008;19(1):13-17.

22. Watson AB, Yellott JI. A unified formula for light-adapted pupil size. J Vis. 2012;12(10):12.

23. Lee JC, Kim JE, Park KM, Khang G. Evaluation of the methods for pupil size estimation: on the perspective of autonomic activity. Conf Proc IEEE Eng Med Biol Soc. 2004;2:1501-1504.

24. Roberts DK, Yang Y, Lukic AS, Wilensky JT, Wernick MN. Quantification of pupil parameters in diseased and normal eyes with near infrared iris transillumination imaging. Ophthalmic Surg Lasers Imaging. 2012; 43(3):196-204.

25. Sobaci G, Erdem U, Uysal Y, Muftuoglu O. Changes in pupil size and centroid shift in eyes with uncomplicated in-the-bag IOL implantation. J Refract Surg. 2007;23(8):796-799.

26. Koch DD, Samuelson SW, Villarreal R, Haft EA, Kohnen T. Changes in pupil size induced by phacoemulsification and posterior chamber lens implantation: consequences for multifocal lenses. $J$ Cataract Refract Surg. 1996;22(5):579-584.

Clinical Ophthalmology

\section{Publish your work in this journal}

Clinical Ophthalmology is an international, peer-reviewed journal covering all subspecialties within ophthalmology. Key topics include: Optometry; Visual science; Pharmacology and drug therapy in eye diseases; Basic Sciences; Primary and Secondary eye care; Patient Safety and Quality of Care Improvements. This journal is indexed on Submit your manuscript here: http://www.dovepress.com/clinical-ophthalmology-journal
27. Keuch RJ, Bleckmann H. Pupil diameter changes and reaction after posterior chamber phakic intraocular lens implantation. $J$ Cataract Refract Surg. 2002;28(12):2170-2172.

28. Dick HB, Aliyeva S, Tehrani M. Change in pupil size after implantation of an iris-fixated toric phakic intraocular lens. J Cataract Refract Surg. 2005;31(2):302-307.

29. Totsuka K, Kato S, Shigeeda T, et al. Influence of cataract surgery on pupil size in patients with diabetes mellitus. Acta Ophthalmol. 2012;90(3):e237-e239.

30. Holladay JT, Praeger TC. Accurate ultrasonic biometry in pseudophakia. Am J Ophthalmol. 1989;107(2):189-190.

31. Fedtke C, Manns F, Ho A. The entrance pupil of the human eye: a three-dimensional model as a function of viewing angle. Opt Express. 2010;18(21):22364-22376.

32. Keating MP. Geometric, Physical, and Visual Optics. 2nd ed. Oxford: Butterworth-Heinemann; 2002:117-118.

33. Charman WN, Atchison DA. Theoretical effect of changes in entrance pupil magnification on wavefront-guided laser refractive corneal surgery. J Refract Surg. 2005;21(4):386-391.

34. Kasthurirangan S, Glasser A. Age related changes in the characteristics of the near pupil response. Vision Res. 2006;46(8-9):1393-1403.

35. Winn B, Whitaker D, Elliott DB, Phillips NJ. Factors affecting lightadapted pupil size in normal human subjects. Invest Ophthalmol Vis Sci. 1994;35(3):1132-1137.

36. Franssen L, Tabernero J, Coppens JE, van den Berg TJ. Pupil size and retinal straylight in the normal eye. Invest Ophthalmol Vis Sci. 2007; 48(5):2375-2382.

37. Lee JC, Kim JE, Park KM, Khang G. Evaluation of the methods for pupil size estimation: on the perspective of autonomic activity. Conf Proc IEEE Eng Med Biol Soc. 2004;2:1501-1504.

38. Wachler BS, Krueger RR. Agreement and repeatability of infrared pupillometry and the comparison method. Ophthalmology. 1999;106(2): 319-323.

39. West KE, Jablonski MR, Warfield B, et al. Blue light from light-emitting diodes elicits a dose-dependent suppression of melatonin in humans. J Appl Physiol (1985). 2011;110(3):619-626.

40. Schnitzler EM, Baumeister M, Kohnen T. Scotopic measurement of normal pupils: Colvard versus Video Vision Analyzer infrared pupillometer. J Cataract Refract Surg. 2000;26(6):859-866.

41. Schor CM. Neuromuscular plasticity and rehabilitation of the ocular near response. Optom Vis Sci. 2009;86(7):E788-E802.

42. Hess EH, Polt JM. Pupil size in relation to mental activity during simple problem-solving. Science. 1964;143(3611):1190-1192.

43. Bradley MM, Miccoli L, Escrig MA, Lang PJ. The pupil as a measure of emotional arousal and autonomic activation. Psychophysiology. 2008;45(4):602-607.

44. Potamitis T, Slade SV, Fitt AW, et al. The effect of pupil dilation with tropicamide on vision and driving simulator performance. Eye (Lond). 2000;14(Pt 3A):302-306.

45. Yang Y, Thompson K, Burns SA. Pupil location under mesopic, photopic, and pharmacologically dilated conditions. Invest Ophthalmol Vis Sci. 2002;43(7):2508-2512.

46. Elliott A, Carter C. Pupil size after extracapsular cataract extraction and posterior chamber lens implantation: a prospective randomized trial of epinephrine and acetylcholine. Ophthalmic Surg. 1989;20(8): 591-594.

\section{Dovepress}

PubMed Central and CAS, and is the official journal of The Society of Clinical Ophthalmology (SCO). The manuscript management system is completely online and includes a very quick and fair peer-review system, which is all easy to use. Visit http://www.dovepress.com/ testimonials.php to read real quotes from published authors. 